\title{
Physical Methods and Parameters for Assessing the Strength, Fatigue, Durability and Damage to a Structural Material
}

\author{
Shtyrov Nikolay \\ Private Research and Production Company LYU, Nikolayev 54020, PO Box 86, Ukraine
}

\begin{abstract}
The methods and criteria of the physical theory of strength are used. The initial physical and mechanical parameters of the strength of steel 45 were determined analytically. Strength, fatigue and damage to steel were calculated for non-stationary mechanical and various thermal loads. The ratio between the physical and generally accepted mechanical parameters of the material strength is determined analytically. The result of the calculation of the new characteristics of the strength of the damaged material is given. The method takes into account plastic deformation, an arbitrary form of stress cycle, temperature mode. Additional physical criteria for evaluating the strength properties are proposed. We use our own calculation programs, which allow us to take into account the changed characteristics of the damaged material for various stress functions. The physical method allows you to analyze and quickly process the rheological data of sensors that control the parameters of the material under load. A method for rapid analysis and comparison of the results of indentation into the material in accordance with ISO 14577 using various indenters is proposed. Physical parameters of the material and new theoretical methods of calculation can be used to assess the properties of materials, monitor the condition and predict the strength and durability of the material of machines during operation.
\end{abstract}

Key words: Stress, strain, strength, physical equation, calculation.

\section{Introduction}

The purpose of the article is to show the main physical parameters, dependencies, calculation methods in the physical structural-energy theory of the strength of a deformed solid (hereinafter DS). The main research results are presented. The equation of physical theory of strength of materials is used. The relationship between physical molar parameters and ordinary mechanical properties and parameters of a deformable solid is shown. An example of a theoretical determination of the initial physical parameters of a material is considered using experimental rheological diagrams of long-term tensile testing of steel 45. A theoretical method is given for constructing generalized standard rheological diagrams of stresses and tensile

Corresponding author: Shtyrov Nikolay, director of private Research and Production Company LYU. deformations. Using physical molar parameters, generalized rheological diagrams, the author analytically determined the mechanical parameters of the strength of steel. The steel fatigue parameters are theoretically estimated at various cyclic loads and different temperatures. Standard fatigue tests are modeled theoretically. A comparison of theoretical and experimental results is given. The prospects for using a physical approach to quickly assess the strength and damage of materials of machines and mechanisms are discussed.

Using the equations and formulas of the physical theory, an objective relationship is established between the physical structural and energy parameters and the usual mechanical properties of strength and deformation characteristics of the material. To this end, an analysis was made of the properties of the rheological functions of stresses and strains obtained experimentally at a low rate of steel deformation 
under tension before fracture. Using the deformation rheological diagram of the uniaxial tension of the material, the properties of the functions of speed and acceleration of the relative irreversible plastic deformations of the form change of the body are analyzed analytically. As a result, generalized formulas are obtained analytically for estimating the initial values of the structural physical parameter and the activation energy of material destruction.

Using the developed theoretical methods, stationary creep equations, physical equations and the dependences of the structural-energetic theory of strength, a theoretical estimation of the initial structural-energetic physical parameters of the strength of a structural material was made. The initial structural parameter $\gamma_{\mathrm{o}}$, the activation energy of destruction $\mathrm{U}_{\mathrm{o}}$ of carbon steel are determined.

Using recognized experimental data, physical theoretical methods, using carbon steel as an example, a generalized analytical physical model of mechanical tests was developed. A generalized rheological function was obtained to simulate tests according to ISO 6892-84, which allows virtual tests of uniaxial stretching of a material before fracture.

Thus, having data on the body temperature $T$, the rheological function $S(t)$ of the actual load in true stresses, the initial physical parameters of the material $\gamma_{\mathrm{o}}, \mathrm{U}_{0}$, using analytical methods of the physical theory, it is possible to determine the values of plastic deformations, damage, the predicted time to failure, etc.

In the physical theory, additional important physics mechanical parameters and properties of the process of irreversible deformation up to the state of material destruction are also considered.

A theoretical analysis and generalization of the properties of force and deformation rheological diagrams of uniaxial stretching of a material are applied. A method for constructing a generalized rheological diagram $S(t)$ of a standard process was obtained, using which physical methods can determine standard characteristics of the limit of proportionality $\sigma_{02}$ (plastic deformation $=0.02 \%$ ), tensile strength $\sigma_{\mathrm{B}}$, time to failure $\mathrm{t}_{*}$, residual deformation $\varepsilon_{\mathrm{r}^{*}}$, plastic deformation rate and other physical and mechanical characteristics of the material for this process.

A theoretical method is proposed for solving an inverse physical problem - calculating the mechanical standard characteristics of steel using physical parameters of strength and a rheological generalized tensile test model according to a standard.

Physical and analytical methods are proposed that allow the theoretical calculation of fatigue characteristics at different frequencies and instrumental temperatures, using the initial physical parameters of the material, the dependence of the theory, the developed algorithms and programs. An example of theoretical calculations of simple mechanical characteristics of carbon steel, the possibility of a physical theoretical method for studying the processes of deformation and destruction of solids is shown.

\section{Materials and Methods}

\subsection{Physical Parameters and Dependencies}

The physical structural-energetic theory of strength (SET) is the result of the theoretical development of the kinetic concept of strength (KCS) of solids [1]. The concept is well known as the Zhurkov formula (1), which determines the time to brittle material failure (durability) for constant stresses and temperatures:

$$
\tau_{*}=\tau_{\mathrm{o}} \exp \left(\mathrm{U}_{\mathrm{o}}-\gamma_{\mathrm{o}} \sigma\right) / \mathrm{RT}
$$

where, $\tau_{*} \mathrm{~s}$ is the durability, $\gamma_{0} \mathrm{~m}^{3} / \mathrm{mol}$ is the structural parameter of the material, $\tau_{0}$ is the period of associated thermal vibrations of the atoms of the body, $\mathrm{U}_{0} \mathrm{~J} / \mathrm{mol}$-is the activation energy of destruction, $\sigma, \mathrm{Pa}$ - is the constant tensile stresses, $\mathrm{R}, \mathrm{J} / \mathrm{mol} \cdot \mathrm{K}$ - is the gas constant, $\mathrm{T}, \mathrm{K}$-constant temperature. 
$\gamma_{\mathrm{o}} \sigma$-the product is the molar energy density, according to one of the three components of the main stresses DS: $\mathrm{W}_{\mathrm{Lo}}=\gamma_{\mathrm{o}} \cdot \sigma, \mathrm{J} / \mathrm{mol}$.

Formula (1) is confirmed for different solid materials in a wide range of stresses and temperatures. Zhurkov's concept is fundamentally different from the previous DS mechanics. The duration of the voltage, temperature, microstructure parameters of the DS structure, etc. are taken into account. The concept uses the DS molar physical characteristics. Previously, the molar parameters, the kinetics of their changes, were considered exclusively in calculations of chemical reactions, materials science, etc. In the concept, the fluctuation of the energy of the atomic bond is considered to be the cause of the elementary damage. It is assumed that the accumulation during the time $\tau_{*}$ of the elementary destruction of bonds in the material, up to a critical level, creates conditions for macroscopic spontaneous brittle destruction of the body [1].

The concept has been successfully applied in calculating the strength of structural elements with cyclic and static voltages [2], shock, pulsed laser loads, earth crust strength, and a number of others [3, 4]. But in these methods there is no physical and theoretical justification for the use of molar characteristics, sound methods for calculating the complex stress state and variable voltages. In Formula (1), the main parameters were taken as empirical.

In the structural-energetic kinetic theory of solid strength (SET), a theoretical substantiation of the formula and Zhurkov parameters (1) was obtained, a physical wave-particle model of destruction and irreversible deformation of the DS [5] was substantiated. The physical theory of strength was obtained from the standpoint of statistical physics and wave theory, analysis and theoretical substantiation of experimental results and empirical formulas of the kinetic concept of the strength of solids. Destruction is considered as an elementary wave-wave process of periodic energy exchange, in small volumes of a solid body, occurring with a characteristic high frequency. This process may be reversible and irreversible. In classical mechanics, phenomenological models of the destruction of hypothetical atomic bond forces in solids (pair potentials, etc.) are considered. The physical theory considers a microscopic process of interaction of elementary kinetic energy flows of de-Broglie wave-quasiparticles, resulting from fluctuations of the interaction of these quasiparticle waves in elementary small DS volumes. The elementary energetic associated volume wave-particle wave interactions of elementary structural units of a macroscopic medium (in terms of mechanics are atomic bonds) are considered. The physical generalized model of the volume interaction of structural units is applicable for solids of different nature, it reasonably replaces the empirical model of "mechanical" atomic binding forces.

In the structural-energetic kinetic theory of solid strength (SET), a theoretical substantiation of the formula and Zhurkov parameters (1) was obtained, a physical wave-particle model of DS destruction was substantiated, a number of fundamental issues of applying physical methods in the concept and theory of strength were solved [5].

In SET, new generalized physical parameters of the DS state, derivatives of these quantities, are proposed, functions are obtained, from which Formula (1) follows. The relationship between the physical molar parameters and the mechanical parameters of the theory of elasticity is shown; a number of well-known experimental dependencies of DS mechanics and the equation of state of an ideal gas (theoretically as a case of the wave-particle thermodynamic system) have been theoretically obtained [6], considering the basic physical molar values in SET.

For simplicity, we consider DS as a heterogeneous single-phase (three-dimensional phase) one-component thermodynamic system in a quasi-equilibrium state. Let the function of principal stresses $\sigma_{1}(t)$ be given for one component of the 
tensor $\sigma_{1}(\mathrm{t})=\sigma(\mathrm{t}),|\sigma|>0, \mathrm{~Pa}$. In this case, DS can be characterized by generalized physical characteristics.

$\operatorname{Sh}(\sigma, \mathrm{t}), \mathrm{m}^{3} / \mathrm{mol}$-is the molar volume of quasiparticles of strength. The volume DS in which for each elementary small characteristic period of time $\tau_{0}$, occurs $\mathrm{N}_{\mathrm{A}}$ characteristic periodic fluctuations of the energy of the interaction of quasiparticle of Broglie waves, Avogadro number $\mathrm{N}_{\mathrm{A}}=6,022 \cdot 10^{22}$ un $/ \mathrm{mol}$.

$$
\mathrm{W}_{\mathrm{L}}=\mathrm{W}_{\sigma} \cdot \mathrm{Sh}, \mathrm{J} / \mathrm{mol}, \mathrm{W}_{\sigma}=\frac{\sigma^{2}}{2 \mathrm{E}}, \mathrm{J} / \mathrm{m}^{3}
$$

where $\mathrm{W}_{\mathrm{L}}(\sigma, \mathrm{t})$, is the molar energy, the state function of DS, E, is the modulus of elasticity.

$$
\mathrm{Gr}=\sigma \cdot \operatorname{Sh}(\sigma, \mathrm{t}), \mathrm{J} / \mathrm{mol}
$$

where, $\mathrm{Gr}$ is the structural-energy potential, the physico-mechanical characteristic of the state of a solid body.

$$
\begin{gathered}
\mathrm{Gr}(\mathrm{t})=0.5 \mathrm{E} \cdot \gamma_{\mathrm{r}}(\mathrm{t}), \quad \mathrm{Gr}_{\mathrm{o}}=0.5 \mathrm{E} \gamma_{\mathrm{ro}} \\
\gamma_{\mathrm{o}}=\mathrm{Sh}(\mathrm{t}=0, \sigma=\mathrm{E})
\end{gathered}
$$

$\gamma_{\mathrm{r}}(\mathrm{t}, \sigma)$ - the root molar volume DS, the structural function of the material $[6,7]$. The state function $\operatorname{Gr}\left(\sigma, T, U_{o}, G r_{o}, t\right)$ reflects the process of the influence of mechanical, heat load on irreversible changes in the material $[6,7]$. The initial value $\mathrm{Gr}_{0}$, for pure metals, of many solids is determined by the Zhurkov method $[2,3]$. For structural materials $\mathrm{Gr}_{0}$, the value is determined in SET by analytical methods, by processing the rheological diagrams of uniaxial tension of the material or indentation data according to ISO 14577 [7].

The relationship between physical parameters and mechanical properties of materials is presented. In SET, dependences Formulas (3) and (4) are obtained, which allows determining plastic deformations of a material at any time instant if the function of true stresses and the initial physical parameters of the material are given:

$$
\varepsilon_{\mathrm{r}}(\mathrm{t})=\int_{0}^{\mathrm{t}} \frac{\mathrm{RT}}{\tau_{*}\left(\mathrm{~W}_{\mathrm{L}}\right) \mathrm{W}_{\mathrm{L}}(\mathrm{t})} \mathrm{dt},
$$

$$
\dot{\bar{\varepsilon}}_{\mathrm{r}}(\mathrm{t})=\frac{\mathrm{RT}}{\tau_{*}\left(\mathrm{~W}_{\mathrm{L}}\right) \mathrm{W}_{\mathrm{L}}(\mathrm{t})}, 1 / \mathrm{s} .
$$

$\varepsilon_{\mathrm{r}}$ - accumulated true irreversible deformations, $\dot{\bar{\varepsilon}}_{\mathrm{r}}$-strain rate for uniaxial deformation. Dependencies (3) and (4) are confirmed experimentally [8].

In SET, a dependency is obtained that allows you to find the current value of the parameter $\gamma_{r}(t)$ for structural materials by processing experimental rheological diagrams $\varepsilon_{\mathrm{r}}(\mathrm{t})$ [7].

$$
\gamma(\mathrm{t})=\frac{\operatorname{RT} \partial\left(\operatorname{Ln} \alpha \dot{\varepsilon}_{\mathrm{r}}\right)}{\partial \sigma}
$$

where $\alpha$ is the normalization factor.

A simple formula is obtained for the analytical evaluation of the initial value of the structural parameter of a structural material according to the analytical processing of rheological diagrams, as a result of uniaxial tension of the sample material.

In SET, a number of other dependencies of the relationship of physical, thermodynamic, and mechanical parameters are obtained, which allows solving problems of DS mechanics by physical methods, confirmed by experimental data, for example, the calculation of the specific number of dislocations, the amount of heat generated during irreversible processes, etc. $[5,6]$.

\subsection{The Basic Equation of Physical Theory}

The SET obtained physical equations and dependencies for the calculation of durability under non-stationary and complex loads, with respect to different molar functions of the DS state [5]. Differential Eq. (5) is written for a structural function $\gamma_{\mathrm{r}}(\mathrm{t}, \sigma)$, a single-component structurally homogeneous, persistent material, the true stress function $\sigma(\mathrm{t})$ is given. The equation was obtained by the author of the article on the basis of the analysis and generalization of two recognized independent fundamental experiments KCS [9].

$$
\frac{\sigma \mathrm{d} \gamma}{\mathrm{dt}}=\frac{\mathrm{RT}}{\tau_{0}} \exp \left(\frac{\gamma_{\mathrm{o}} \sigma-\mathrm{Uo}}{\mathrm{RT}}\right), \mathrm{j} / \mathrm{s} \cdot \mathrm{mol}
$$


Border conditions: $U_{o}, \gamma_{o}$. Condition of destruction:

$$
\mathrm{U}_{0}-\gamma(\mathrm{t})|\sigma(\mathrm{t})|=0, \quad \mathrm{~T}=\mathrm{const}
$$

In the SET, further physical methods are developed for taking into account the influence on the strength and durability of the factors of all-round pressure, radiation, electric current, a number of formulas are obtained for assessing these factors on the durability, etc. Using the example of analyzing the properties of an experimental carbon steel rheological diagram, we show the possibilities of a physical theory to solve analytically the problems of estimating standard mechanical characteristics, material damage, determine modified standard characteristics of a damaged material, fatigue properties, durability, etc. for alternating stresses, material temperature. We use equations, theory dependences, developed programs for solving equations of physical theory. These programs allow you to see the values of physical parameters of strength, the speed of their change under different loads, etc.

\section{Results}

\subsection{The Method of Theoretical Determination of the Initial Physical Parameters of Steel 45}

We use rheological diagrams of slow stretching $\sigma(\mathrm{t})$ of the sample, force (Fig. 1A) and deformation (Fig. 1B). They were obtained on a special testing machine [10]. The strain rate in the initial section $\dot{\varepsilon}$ $=0,53 \cdot 10^{-4}, \mathrm{~s}^{-1}$. The duration of the deformation process is about $1,000 \mathrm{~s}$. The process is isothermal. For comparison, the usual rheological curves $\sigma(\mathrm{t})$, $\varepsilon(t)$,obtained by the method ISO6892-84 are shown schematically alongside, recorded in time, until the specimen was destroyed. The standard process time is 2-5 seconds to failure. Test parameters are recorded in digital form and Excel spreadsheets against time.

Using these experimental results, Eqs. (3) and (4), physical Eq. (5), and dependence Eq. (6), a theoretical estimation of the structural-energetic physical parameters of the strength of steel 45 was made. The initial structural parameter $\gamma_{\mathrm{o}}=\gamma\left(\mathrm{t}_{02}\right)=1,23 \div 1,28 \cdot 10^{-4}$ $\mathrm{m}^{3} / \mathrm{mol}$ was determined. The activation energy of destruction $\mathrm{U}_{\mathrm{ol}}=1,38 \cdot 10^{5} \mathrm{j} / \mathrm{mol}$ - to the yield point, $\mathrm{U}_{\mathrm{o} 2}=2,05 \cdot 10^{5} \mathrm{j} / \mathrm{mol}$ - to the limit of strength. Using the obtained physical parameters, the inverse problem was theoretically solved, the initial deformation diagram was constructed, the basic parameters of deformation by tensile steel 45 were determined to failure for a given stress function according to ISO6892-84 [11], thus, the verification of the first stage of calculations.

\subsection{Evaluation of Standard Mechanical} Characteristics of ISO6892-84 Using the Initial Physical Parameters of the Material

The physical theory was used to estimate the limits of proportionality and strength, residual deformations of steel 45 . The analytical relationship between the mechanical characteristics of strength and the physical parameters of the strength of steel 45 was used. The
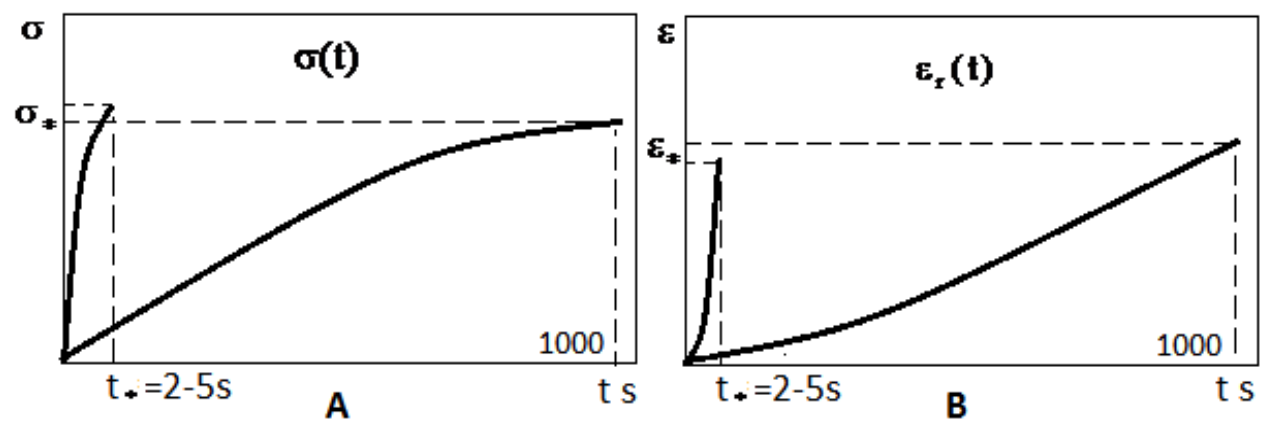

Fig. 1 Conditional rheological diagrams of the sample stretching to failure $t_{*}$, the standard process time to failure is $2-5 \mathrm{~s}$. (A) $\sigma(\mathrm{t})$ force diagrams, (B) $\varepsilon_{\mathrm{r}}(\mathrm{t})$ deformation diagrams. 
initial physical structural and energy parameters $\gamma_{\mathrm{o}}$, $\mathrm{U}_{\mathrm{o}}$ obtained earlier were used. A generalized model of the rheological stress diagram for uniaxial tension of steel to failure, provides the necessary average rate of relative deformations of the material

$\dot{\bar{\varepsilon}}=1,375 \cdot 10^{-3} 1 / \mathrm{s}$, is applied according to ISO6892-84. Calculation results:

$\sigma_{02}=449, \mathrm{MPa}$, limit of proportionality; $\mathrm{t}_{02}=1.56$, s; $0.0021(0.21 \%)$;

$\mathrm{S}_{*}=1060 \div 1200 \mathrm{MPa}, \mathrm{Pa}$ true tensile strength; $\mathrm{t}_{*}=3.7-4.4 \mathrm{~s}$, time to failure;

$\varepsilon_{\mathrm{r} *}=0.16-0.22$, residual deformations at fracture; $\sigma_{\mathrm{B}}=778 \mathrm{MPa}$, conditional tensile strength.

Experimental characteristics of carbon steel 45, in the state of delivery [12]; $\sigma_{\mathrm{B}}=748, \mathrm{MPa}, \mathrm{S}_{*}=$ $1173, \mathrm{MPa} ; \sigma_{02}=412 \cdot 10^{6} \mathrm{~Pa}$. Residual elongation $=$ $19 \%$.

\subsection{Theoretical Estimation of Steel Fatigue} Parameters 45, for Given Various Cyclic Stresses, Temperature Regimes

Using the dependences of the physical theory (2-5), the initial molar physical parameters of steel 45, the fatigue tests of the material ISO 14577-1: 2002 [13] were analytically simulated, and the fatigue limit $\sigma_{-1 p}$ of carbon steel 45 was determined [7]. The influence of load frequency, temperature on durability, endurance limit has been estimated (Fig. 2). The results are consistent with the reference characteristics of the material, confirming the adequacy of the proposed physical model of fatigue failure. Reference characteristic of the endurance limit of steel 45 (GOST 1497-84) is 190-250 MPa (tensile pulsations).

\subsubsection{Indentation}

Using rheological indentation diagrams, the SET made physical calculations of the physical and standard mechanical characteristics of the strength of 45, 15Х2НМФА steel. The methods of physical theory were used, additional physical parameters of the process were taken into account, based on the data of instrumented indentation according to ISO 14577-1.2002. Experimental data obtained at the UTM-20HT installation [14] for Brinell and Vickers indenters are used in the work. A general physical

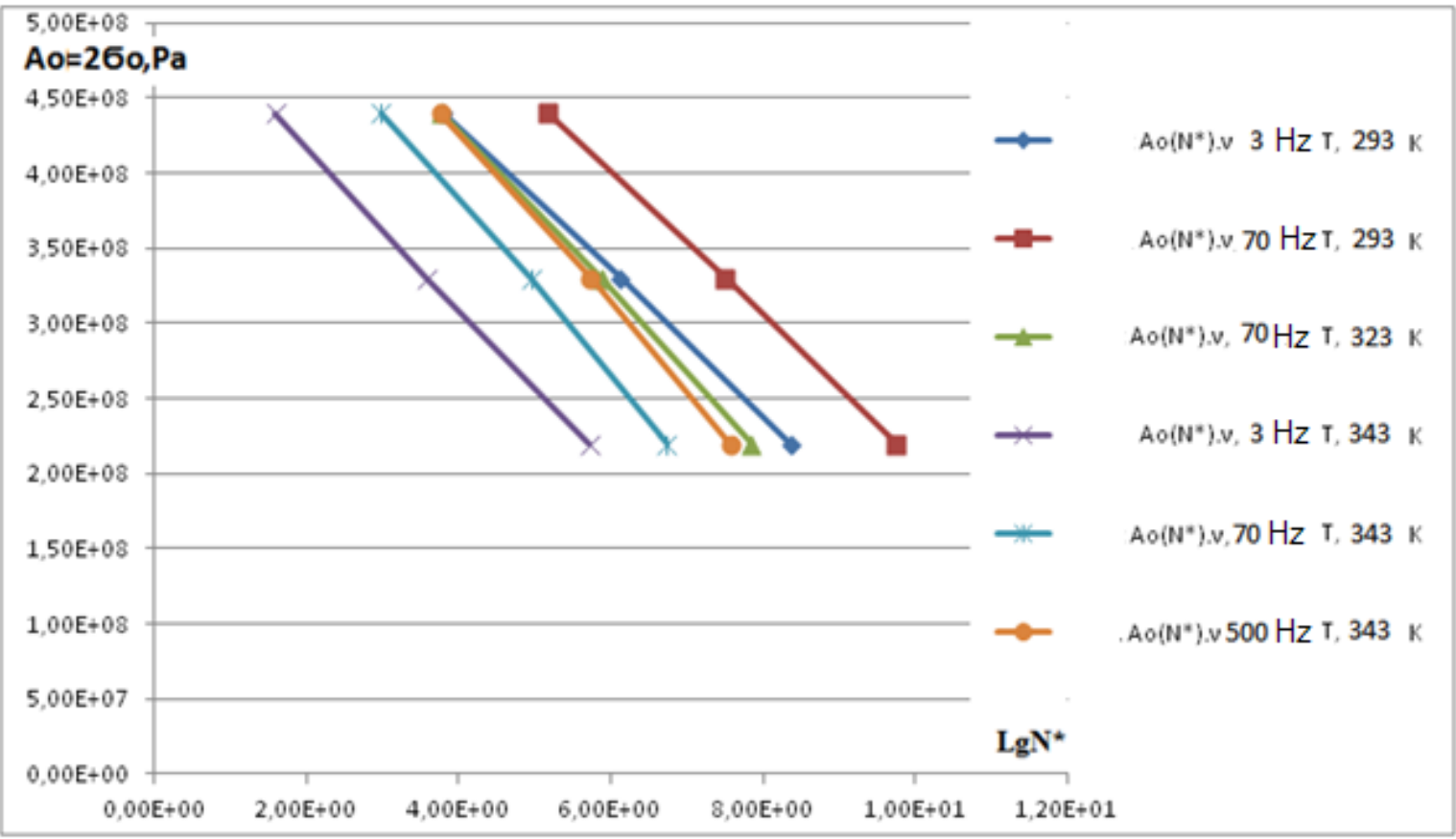

Fig. 2 The dependence of the amplitude of the magnitude of the cyclic tensile stress $A_{0}$ on the number of cycles to the destruction of the material $\mathrm{N}_{*}$. Frequencies 3, 70, $500 \mathrm{~Hz}$. Temperature: 293 (20), $323(50), 343$ (70), Celsius temperature in brackets. Form of uniaxial tension cycle stress: $\sigma(t)=\sigma_{0}\left(1.001-\cos B_{s} t\right)$. 
analytical method for analyzing and processing test results, with various tools and indentation efforts, is proposed. The method is intended for an approximate assessment of the physical parameters of the material and standard mechanical characteristics of strength. By this method, using the simplified DS model, the ultimate strength and yield strength of steel 45, 15X2НМФА were determined.

\section{Discussion}

The DS model represents a physical medium consisting of quasiparticles with molar energy of CFLs. This approach made it possible to form an understanding of the state of the physical external and internal boundaries of the structure and the energy state of the material. This method is fundamentally different from the mechanical criteria of the limiting states of the material. This approach allows analytically describing the processes of irreversible deformation (plastic deformation), formation of a free surface (defect, crack, rupture), heat generation, up to brittle destruction of the body [5, 6]. The dependences of the theory are confirmed by the well-known empirical formulas of DS mechanics and the kinetic concept of strength. The physical properties of the molar structural-energetic model of deformation and destruction of the body are, in a certain sense, universal, applicable to describe the destruction of bodies of different physical nature (amorphous, crystalline, etc.). To describe the processes in DS, the physical equilibrium equation of molar energy is used. In theory, the connection of physical parameters with the parameters of DS mechanics is established. Physical energy characteristics are considered: the molar energy (molar thermodynamic potential), the molar volume, the change in the molar volume, their derivatives, the power, the speed of the process, and other physical parameters DS. Additional physical, actually controlled parameters are proposed, for example, the specific surface of the body, the specific power (vector) of structural destruction of the material, etc. The proposed parameters and functions form new criteria for comparing the properties of experimental samples and bodies of various sizes and shapes, types of indentation tools. The criteria are used to compare the properties of the state of a deformed body as a statistical thermodynamic system consisting of three conventional elements: material (substance), sample (body), load (various factors). Known experimental kinetic equations and dependences follow from the theoretically obtained wave equilibrium equation of molar energy. The basic wave equation of the physical theory of strength of an ideal physical body in a particular case turns into a classical equation of state for one mole of an ideal gas. The theory considers the rheological (in time) characteristics of the processes. The connection of the macro parameters of stress, pressure, temperature, volume, deformation, free surface area with microscopic statistical molar energy, physical properties of waves of quasiparticles and other parameters of the atomic level has been established.

The performed calculations show the physical picture of the connection between the mechanical parameters of plastic deformation of the material and the physical parameters of the deformed solid. It is shown that it is possible in principle to apply new physical methods, instead of phenomenological approaches, when solving problems of DS mechanics. A more accurate and detailed calculation of the mechanical parameters and physical characteristics of DS is possible. To do this, it is necessary to calculate the physical parameters over the entire deformation diagram, to use other more complex methods of numerical solution.

\section{Findings}

With the rheological diagrams of the true stresses $S(t)$ and deformations $\varepsilon(t)$, the process of stretching a sample of a material (by oscillogram, spreadsheet, etc.) before failure, or the results of indentation according to ISO $14577-1.2002$, it is possible to determine the 
initial physical parameters using physical methods, then we determine the standard characteristics of strength and fatigue, simulating the standard test procedures. Physical methods can theoretically estimate the parameters of strength, fatigue, material durability for an arbitrary given function of stress and temperature. A theoretical account of the influence of additional physical factors on the process of damage accumulation in the material is possible.

The developed theoretical and programmatic methods allow the rapid assessment of the state of the physical and mechanical parameters of the material directly in the structural elements of existing machines and mechanisms. For this purpose, you can use the appropriate sensors to control the parameters of deformation, temperature, etc. Data can be accumulated and stored, using the communication mode with information processing devices provided by the appropriate software algorithms for physical calculations of material state parameters.

For interested organizations, we propose a joint further development, the use of the proposed physical calculation methods, programs for analyzing and monitoring the state of strength, damage to structural elements of dynamic devices, machines in complex non-stationary conditions and operation.

\section{References}

[1] Zhurkov, S. N. 1980. "K voprosu o fizicheskoy osnove prochnosti." FTT 22 (11): 3344-9.

[2] Petrov, M. G., and Ravikovich, A. I. 2004. "O deformirovanii i razrushenii alyuminiyevykh splavov $\mathrm{s}$ pozitsiy kineticheskoy kontseptsii prochnosti." PMTF 45 (1): 151-61.

[3] Kartashov, E. M. 1991. "Sovremennyye predstavleniya kineticheskoy termofluktuatsionnoy teorii tverdykh polimerov." VMS 27: 3-111.

[4] Potapova, L. B., and Yartsev, V. P. 2005. "Mekhanika materialov pri slozhnom napryazhennom sostoyanii."
Moskva. Mashinostroyeniye, 244.

[5] Shtyrov, N. A. 2014. "Deformirovaniye i razrusheniye imeyushchikhsya tel $\mathrm{s}$ pozitsiy kineticheskoy strukturno-energeticheskoy teorii prochnosti. 5ya Mezhdunarodnaya konferentsiya mekhanika razrusheniya i prochnost' materialov." L'vív. FMI, pp. 63-70.

[6] Shtyrov, N. A. 2013. "Fizicheskiye parametry i svoystva deformirovannogo tverdogo tela v strukturno-energeticheskoy kineticheskoy teorii prochnosti. Primery resheniy zadach vysokoy prochnosti i ustalosti." Energiya dolgovechnosti 5: 6-30. http://energydurability.com.

[7] Shtyrov, N. A. 2018. "Theoretical Assessment of the Mechanical Characteristics of the Strength of Steel Using the Dependencies and Parameters of the Physical Theory of a Deformed Solid." 7: 14-31. http://energydurability.com.

[8] Regel', V. R., Slutsker, A. I., and Tomashevskiy, E. G. 1974. "Kineticheskaya priroda prochnosti tverdykhtel." Moskva, Nauka, 560.

[9] Shtyrov, N. A. 1987. "Opredeleniye fizicheskikh usloviy razrusheniya polikristallicheskikh tel pri nestatsionarnom tsiklicheskom rastyazhenii. Sbornik nauchnykh trudov. Stroitel'naya mekhanika korablya." Nikolayev, NKI, 74-84.

[10] Degtyarev, V. A. 2005. "Vliyaniye predvaritel'nogo plasticheskogo deformirovaniya na mekhanicheskiye kharakteristiki stali 45i splava D16T pri staticheskom i tsiklicheskom nagruzhenii." Problemy prochnosti 4: 33-45.

[11] ISO 6892-1:2009. Metallic Materials-Tensile Testing-Part 1: Method of Test at Room Temperature.

[12] Gladkov, V. M., Kudryavtseva, A. A., and Sukhin, V. I. 1977. "O sootnoshenii mezhdu staticheskimi i mekhanicheskimi kharakteristikami i impul'snym napryazheniyem $\mathrm{v}$ metallicheskikh sterzhnyakh." $P M T F$ 5: $135-7$

[13] ISO 14577-1:2002. "Metallic Materials-Instrumented Indentation Test for Hardness and Materials Parameters. Test Method."

[14] Kharchenko, V. V., Rudnitskiy, N. P., Katok, O. A., Negovskiy, A. N., Drozdov, A. V., and Kutnyak, V. V. 2007. "ustanovka dlya opredeleniya mekhanicheskikh kharakteristik konstruktsionnykh materialov metodom instrumentirovannogo indentirovaniya." Nadíyníst' í dovgovíchníst' mashin í sporud 28: 140-7. 